\title{
Social Representations Theory
}

\author{
A New Theory for Media Research
}

\author{
Birgitta Höijer
}

\begin{abstract}
This article argues that the theory of social representations can give valuable contributions to media research. It offers a new theory-based approach for studying how the media and citizens socially represent societal and political issues colouring our age, or some specific time period. Two fundamental communicative mechanisms - anchoring and objectification - are posited by the theory. These mechanisms, with a set of subcategories, are presented and it is shown how they can be used as conceptual analytical tools in empirical analysis. Concrete examples are given from a study on climate change and the media.
\end{abstract}

Keywords: social representations, media research, communicative mechanisms, anchoring, objectification, climate change

\section{Introduction}

The theory of social representations, first formulated by Serge Moscovici, has influenced researchers from varying disciplines, but is still quite unknown to media researchers. The aim with this article is to introduce the theory and its communicative concepts and make them useful for media studies. The theory offers a new approach for studying how the media and citizens construct societal and political issues colouring our age, or some specific time period. Examples will be given from studies of climate change and the media (Berglez, Olausson \& Höijer 2009; Höijer 2010; Olausson 2010).

Shortly speaking, social representations are about processes of collective meaningmaking resulting in common cognitions which produce social bonds uniting societies, organisations and groups. It sets focus on phenomena that becomes subjected to debate, strong feelings, conflicts and ideological struggle, and changes the collective thinking in society. As a theory of communication it links society and individual, media and public. The theory is relevant for media-and communication research in several ways. It specifies a number of communicative mechanisms explaining how ideas are communicated and transformed into what is perceived of as common sense. This touches the very heart of mediated communication - how the media naturalizes social thinking and generates collective cognition. The theory offers the possibility to develop a theoretically based model of analysis. This is exactly the aim with the present article. 


\section{Historical Origin of the Concept}

There is a link between the concept of social representations and Durkheim's concept "collective representations" which refers to common ways of conceiving, thinking about and evaluate social reality.

According to Moscovici (2000) this concept by Durkheim is, however, too static in relation to how we should understand contemporary society. It does neither catch the dynamics of and changeable character, nor the variability and plurality of social cognitions of the age in which we now live, he claims. To include all this he therefore suggests the new concept "social representation". As noted by Markova (2003: 121) social representations may even be considered as "thoughts in movement" developing through communication.

Moscovici studied the spread of psychoanalytic thinking by the media in the French society and the transformation into common sensical social representations (Moscovici 2007/1961). Such representations of health and unhealthy are typical areas in which scientific knowledge has an important role. A contemporary issue of great significant is climate change in which we can observe how science, politics, mass media and everyday knowledge meet and new social representations emerge.

According to Moscovici (2000) also individuals contribute to the formation of social representations in the interplay between social structure and individual. In modern societies the individual has some autonomy and assimilating social representations may simultaneously modify them. Individuals are "set free" from traditional binding social structures such as family, social class, and religion, which earlier guided thinking and behaviour (Beck \& Beck-Gernsheim 2001; Giddens 1994). There is a greater degree of choice concerning alternative ways of living and of strategies for how to get there. As put by Moscovici:

[...] individuals are confronted with a great variety of specialized knowledge on the part of groups to which they belong. Each individual must make his selection at a veritable open market of representations. (Moscovici 1984a: 963)

By giving the individual some room the theory of social representations avoids social determinism and opens for processes of transformation. But still the individual is mainly embedded in and formed by social structures.

With the epithet "social" Moscovici wants to emphasize how representations arise through social interaction and communication between individuals and groups. "Social" also marks that the contents of representations are social. They reflect, in different ways, historical, cultural and economic contexts, circumstances and practices.

\section{What are Social Representations?}

Social representations are about different types of collective cognitions, common sense or thought systems of societies or groups of people. They are always related to social, cultural and/or symbolic objects, they are representations of something. There is no clearcut definition used by the advocates, and Moscovici himself gives a number of definitions:

Social representations $[\ldots]$ concern the contents of everyday thinking and the stock of ideas that give coherence to our religious beliefs, political ideas and the 
connections we create as spontaneously as we breathe. They make it possible for us to classify persons and objects, to compare and explain behaviours and to objectify them as part of our social setting. While representations are often to be located in the minds of men and women, they can just as often be found "in the world", and as such examined separately. (Moscovici 1988: 214)

A social representation is a system of values, ideas and practices with a twofold function: first, to establish an order which will enable individuals to orientate themselves in their material and social world and to master it; and secondly to enable communication to take place among members of a community by providing them with a code for social exchange and a code for naming and classifying unambiguously the various aspects of their world and their individual group history. (Moscovici 1973: xiii)

[...] from the dynamic point of view social representations appear as a "network" of ideas, metaphors and images, more or less loosely tied together. (Moscovici 2000: 153)

Social representations are not to be seen as logical and coherent thought patterns. They may instead be full of thought fragments and contradictory ideas. With the concept cognitive polyfasia social representations theory refers to the fact that everyday thinking about something may be characterized by different, sometimes opposite, forms of thinking.

To deal with the tricky question of how collectively shared social cognitions must be to qualify as social representations, Moscovici makes a distinction between hegemonic representations, emancipated representations and polemic representations. Hegemonic representations are shared by most of the members of a political party, a nation, or other structured macro unit. They are uniform and 'prevail in all symbolic or affective practices' (Moscovici 1988: 221). In contemporary society climate change conceived of as a threat towards human life and society may be an example of hegemonic social representations. Politicians generally agree that it is a severe problem, the media reporting is dominated by certainty about the existence of anthropogenic climate change (Olausson 2009, 2010), and the public at large has adopted the same view (Berglez, Höijer \& Olausson 2009). Emancipated representations relates to subgroups that create their own versions with "a certain degree of autonomy with respect to the interacting segments of society" (Moscovici 1988: 221). One example could be representations of health and illness in traditional and alternative medicine. These representations may partly be complementary and the public may pick up ideas of both and combine with their own experiences of health and illness. Polemic representations, at last, are related to social conflicts, struggles between groups, and controversies in a society. They are determined by "antagonistic relations" and "intended to be mutually exclusive" (Moscovici 1988: 221), such as political ideas of liberalism and communism. The classification of social representations into these three categories is however, as much classification, somewhat vague, not least because ideas and social thinking is complex and often heterogeneous. As mentioned above social representations are multifaceted and may even be intrinsically contradictory.

What kind of collective cognitions does the theory of social representations have in mind? The following remarks may be made: 
1. Social representations refer to cognitions stamping the collective thinking of society. Of special interest are phenomena that in different ways diverge from traditional views, create tensions in society and challenge everyday life of citizens, groups and institutions. Such phenomena are especially well suited for studying how old ideas are modified and transformed and new social representations are produced by public debate. We easily find examples in today's society, which go through many quick changes related to, for example, new communication technology, biotechnology, environmental risks, global market, terrorism and violence.

2. As put by Moscovici (2000: 160) social representations "participate each time in the global vision a society establishes for itself", and operates at different levels, including large communities like the nation and small subgroups of people. We may here, as noted by Olausson (2010), see a connection to the concept of ideology, especially current theories concentrating on ideologies in the plural form, and as sense making practices of society and everyday life (Fairclough 1992; Hall 1986; 1995).

3. Social representations are complex and holistic. They may be seen as "theories", "network of ideas", metaphors and images that include emotions, attitudes and judgements. They are, further, embedded in communicative practices, such as dialogues, debates, media discourses and scientific discourses (Marková 2003).

4. Social representations refer to cognitions in communication, not least in public debate. Moscovici (2007/1961) early on here emphasized the role of the media in the growth of new social representations, while Marková (2003) especially emphasizes dialogical communication in groups and between individuals.

\section{Communicative Mechanisms}

Social representations theory specifies how collective cognitions are produced and transformed through communication with a focus on the socio-cognitive processes or mechanisms involved. On one hand all human interaction presupposes collective cognitions, that is, social representations. On the other hand individuals and groups produces social representations through social interaction and communication.

According to Moscovici (1984b: 7-10) there are two functions of representations. They conventionalize objects, persons and events we are meeting by giving them a specific form, localize them to a given category, and gradually establish them as distinct and shared cognitions. They are also prescriptive in the sense that they through social structures and traditions are forced upon us. Although we incorporate them into our individual minds, as individuals we rethink collective cognitions. It is important, however, to note that individuals and groups can rework and transform collective cognitions. The idea about a basic link between the collective and the individual, between the present and the past, and between the known and the unknown permeate the theory of social representations. As Moscovici puts it about the relationship between the present and the past:

In many respects, the past is more real than the present. The peculiar power and clarity of representations - that is of social representations - derives from the success with which they control the reality of today through that of yesterday. (Moscovici 1984b: 10) 
All representations aim to "make something unfamiliar, or unfamiliarity itself, familiar" (Moscovici 1984b: 24). The theory proclaims two basic socio-cognitive communicative mechanisms that generate social representations: anchoring and objectifying. The first mechanism, anchoring, makes the unknown known by bringing it into a well-known sphere of earlier social representations so that we may compare and interpret it. The second mechanism, objectifying, makes the unknown known by transforming it into something concrete we may perceive and touch and thus control. These mechanisms will be presented more thoroughly below.

\section{Anchoring}

By communication social representations are anchored again and again in other social representations. This is a kind of cultural assimilation by which new social representations are incorporated into the well-known ones simultaneously as the latter ones are transformed by the new ones. Gradually then the unfamiliar ideas become well-known ideas and part of the collective frames of references of a society. In short anchoring means that new ideas or phenomenon are related to a well-known phenomenon or context. Stuart Hall is touching upon such a mechanism in his classical work "Encoding and decoding in the television discourse".

New, problematic or troubling events, which breach our expectancies and run counter to our "common-sense constructs", to our "taken-for-granted" knowledge of social structures, must be assigned to their discursive domains before they can be said to "make sense". The most common way of "mapping" them is to assign the new within some domain or other of the existing "maps of problematic social reality”. (Hall 1973/1999: 57)

Hall's "common-sense construct" and "taken-for-granted knowledge" in the quote above are close to the concept of social representation, and the "mapping" mechanism he describes is basically an anchoring mechanism by which something new is attached to something already known. He however does not dwell any further into this as done within social representations theory.

We may here differentiate between a number of anchoring mechanisms: naming, emotional anchoring, thematic anchoring, metaphoric anchoring and anchoring via basic antinomies.

\section{Naming}

A most common way of giving the foreign or unknown phenomenon a more well-known face is to name it. By naming something, "we extricate it from a disturbing anonymity to endow it with a genealogy and to include it in a complex of specific words, to locate it, in fact, in the identity matrix of our culture" (Moscovici 2000: 46). In this way the phenomenon is liberated from secrecy and incomprehensibility. A new political group may be named as terrorists, a new ill-health is called the Black Death of our age, the complex scientific phenomenon climate change may shortly be labelled as the weather, and so on.

Naming often appears in headlines and introductions in the media, and even a vague naming may liberate the unknown from total incomprehensibility. In a series of articles 
about climate change of a Swedish tabloid the complex phenomenon simply was named as "climate threat", "weather", "weather alarm", or "the catastrophe" (Aftonbladet 061101-061130). A British newspaper named a pro-vegan campaign focusing meat eaters' role in causing global warming as "hot campaign" (headline: "Heather Mills launches HOT! Campaign” Guardian.co.uk, November 19, 2007).

These acts of namings forge the abstract issue of climate change into recognizable frames of references, or as Moscovici (2000: 46) puts it, locate it in the identity matrix of our culture. Weather is a most common topic of everyday small talk, a lot of people are documenting their own weather observations in diaries, and the weather inevitably affects everyday life. It is everybody's concern. And we do not want the weather to be too hot, or too cold, or too stormy, etc. Words as "threat", "alarm", "hot" or "catastrophe" brings in a dramatic dimension and anchors the issue in well-known media discourses of threat, catastrophe and alarm reports. A number of studies have confirmed that the media increasingly supply their audiences with such reports (Altheide 2002; Robertson 2001).

With his special interest in science and everyday thinking, Moscovici argues that naming is necessary to as well thinking and communication as to social cooperation in a society, and he insists that naming neither should be seen as biasing or diminishing of the original object or phenomenon. Instead he points out that naming may enrich the object and give it new dimensions and qualities (Moscovici 2000).

Classifying and naming sometimes may, however, as Lippman (1998/1922) once noted be strongly connected to processes of stereotyping. Naming someone as a foreigner, a deviant or a fundamentalist, or naming a behaviour an act of madness or a terror attack are not neutral classifications. To put it in the wordings of Lippman (1998/1922: 119 ) such namings rather are "loaded with preferences, suffused with affection or dislike". Stereotyping is specifically related to the naming of social groups and to questions of inclusion and exclusion, discrimination, power and domination (Pickering 2001). Stereotyping "creates the illusion of precision in defining and evaluating other people", and "they are then fixed into marginal positions or subordinate status and judged accordingly" (Pickering 2001: 5).

Stereotypical naming is doubly fraudulent. Firstly, the "Other" is attributed taken for granted negative characteristics, which we conceive as naturalized. The naming therefore give an illusion of being realistic, that is, we do not see them as social constructions. It is so. Secondly, stereotypical namings confirm themselves when, as they are, used over and over again. It really is so.

\section{Emotional Anchoring}

Emotional anchoring is an attachment mechanism that is not specifically pointed out in the theory of social representations although Moscovici now and then addresses emotions. For example in his writings about social representations of money he brings in emotions of passions and desire (Moscovici 1993). Also in Jodelet's (1991) work on madness emotional aspects are discussed, and Joffe (2002: 568-569) argues for that social representations theory "keeps a space for symbols, infused with an emotional valence. It is emotion that motivates the formation of particular SRs [social representations]". Explicitly, however, very little has been written about the role of emotions. This fact ha also been noted by Joffe (2002: 569): "the role of emotion has received surpris- 
ingly little attention ". I will here argue for the need to more explicitly take emotions into consideration in social representations theory. Emotional anchoring then refers to a communicative process by which a new phenomenon is fastened to well-known emotions. By this the unknown gets recognizable as, for example, a threat or a danger to fear, something to worry for, or as something nice and pleasurable. As shown by psychological research emotions may help us to interpret and judge social situations and objects (Bless, Fiedler \& Struck 2004). The mass media willingly exploit this, often maybe in superficial and speculative ways. Social phenomena, events or courses of events are anchored in feelings of fear or an approaching threat, or in feelings of anger, pity or compassion. According to Furedi (2006: xiii) the increasing stream of scare stories in the media are even transforming Western culture into a culture of fear in which "fear feeds on itself and creates the disposition to speculate about other hazards lurking around the corner". Climate change has found to be anchored by the media in a mixture of wellknown emotions of fear, hope, guilt, compassion and nostalgia (Höijer 2010). By this is the scientific phenomenon of climate change turned into a social representation we can compare with other current social phenomena attached to similar emotions such as terrorism or a number of environmental risks. The study concluded: "in short we may regard climate change as something to collectively fear, but there is hope if we behave in a climate friendly fashion. If we do not, we should feel guilt. Media further invites us to feel compassion for endangered species and nostalgia for the idyllic past we are about to lose" (Höijer 2010).

Emotional anchoring may be embedded in the language used, and/or in the photographic pictures or illustrations. The example below illustrates how a tabloid news paper by explicitly putting blame on the individual who does not behave climate friendly anchored climate change in emotions of individual and collective guilt. Guilt is a socially constructed emotion and concerns violations of social codes and norms (Giddens 1991), in this case an implicitly proclaimed code of avoiding Brazilian meat, cacao and soap.

You are eating up the forest ... Have you bought Brazilian meat or cocoa? There is a large risk that you are contributing to climate change. ... Swedish consumers could be supporting the destruction of the rain forest when they buy popular Brazilian meat, cocoa or soap. (Aftonbladet 061110)

Emotionally anchoring may be related to other forms of anchoring or to processes of objectifications (see below). For example, naming climate change as "climate threat", or talking about biotechnology in terms of pollution metaphors (Levidow 2000) anchor these phenomena in emotions of fear and anxiety.

\section{Thematic Anchoring}

Anchoring may also take place at more basic thematic levels by the use of underlying categories of meaning, antinomies such as life/death or culture/nature etc., or by the use of metaphors.

Moscovici $(2000 ; 2001)$ uses the concept of theme to catch the structural in-depth levels of social representations. He argues that underlying collective, general patterns of thinking or primary ideas in interplay with specific contexts generates and structures new social representations. These so called themes, or themata in plural (Markova 2003; 
Moscovici 2000), are in themselves socially and culturally constructed and maintained by social processes. According to Moscovici (2000: 163) they "have been created by society and remained preserved by society". Since themes "never reveal themselves clearly" (Moscovici 2000: 182) the analysis of talk, interviews, or media products often must move beyond the specific language and visuals used.

Themes may be conceived of in ways that come close to the concept of ideology regarded as common sense thinking or taken-for-granted ideas in a society or among groups (cf., Billig 1991; van Dijk 1998) for example democracy, human rights or equality (Moscovici 2001). A number of such underlying themes may be identified in analyses of the media. Continuing with examples from climate change a study found that individualization and nationalization were two prominent themes, (in the referred study also labelled ideological horizons), in Swedish news media (Berglez, Höijer \& Olausson 2009). The following example shows how the theme of self-glorification nationalism takes place in the reporting on climate change. The glorification is present in wordings such as "the one country in the world" and "if we cannot make it, nobody else probably will”:

Sweden is perhaps the one country in the world that most easily can get rid of its oil dependency. ... If we cannot make it, nobody else probably will! We have the chance to prove that it is possible. (Aftonbladet 061102)

Themes may also be assigned to more universal ideas inscribed into language (Moscovici 2000). Taking this as her starting point Markova (2003) has developed the concept of theme from the ontological position of a dialectical or dialogical human consciousness based on the ability to imagine and communicate with the Other.

\section{Anchoring in Antinomies}

Dialogicality means, according to Markova (2003), that sense making is founded on a capacity to make distinctions, to think in oppositions, polarities, or antinomies. Similar to this Billig (1993) claims that human thinking is based on capacity to negate: accept versus turn away, justify versus criticize, etc. This creates tensions and dynamics in society, which may lead to change and development. In all societies antinomies such as life/death, human being/nature, we/them, fear/hope, freedom/oppression, and so on exists.

In specific socio-historical contexts antinomies related to a social phenomenon may become a source of tension, conflict or problem and the phenomenon part of public debate. It is in such situations that new social representations are developed, according to Markova (2003).

Analysing oppositional distinctions or antinomies thus turns focus to intrinsic tensions, which may be especially marked in periods when new social representations develop. Taking social representations of climate change as a case, antinomies such as certainty/uncertainty, threat/hope, guilty/not guilty, nature/culture, global/local may organize the discourse (Höijer 2008; Olausson 2010). For example the distinction guilty/ not guilty was reflected over and over again in the reporting on climate change of a Swedish tabloid newspaper (Höijer 2010). The grown-up world was presented as guilty, in principle all adults in the West: "If everyone lived as we do in the West it would take 
five planets to maintain our consumption of natural resources" (Aftonbladet 061116 ), while the innocent ones were children and animals: "What do you tell your sons, three and five years old, about the climate threat?" (Aftonbladet, 061110); "The baby walrus draws its final breath ... a victim of climate change in the Arctic Ocean" (Aftonbladet, 061108). Olausson (2010) found that underlying Swedish media further was an antinomy or oppositional distinction between us/them. In her discussion of how a European identity is constructed in news media on climate change she suggests that this is established:

by means of the depiction of a conflictual relationship between "Us", the EU, who acknowledge climate change as a serious threat and want to take action against it, and "Them", the USA, who refuse to even discuss regulations. (Olausson 2010)

The relationship between themes and antinomies is somewhat unclear in the theory.

Moscovici (2000) considers themes as "basic ideas", "pre-existing thought", or "primary ideas" while according to Markova (2003) antinomies are more basic also underlying themes. This makes sense if we for example think about ideological themes such as nationalism or individualism, which are hard to conceive of without the counterparts of internationalism or collectivism. In analysing a specific discourse, however, anchoring a social issue in a specific theme (e.g. individualism) may dominate the discourse and its counterpart (collectivism) may be discursively absent. If we emphasize the concrete communication practices thematic anchoring may occur without anchoring in antinomies.

It is worth noting also that anchoring in antinomies may appear without thematic anchoring since "not all antinomies of thinking become themata" (Markova 2003: 184).

\section{Anchoring by Methaphors}

Metaphors make things and phenomena comprehensible by imagining them as something else, for example "life is a journey" or "time is money". A study on social representations of the EU found that people used metaphors such as "milk lakes" and "butter mountains", originating from the media, when referring to food surpluses within the EU (Wagner \& Hayes 2005). The media reports on "human shields" in wars and conflicts, "war" and "sport" metaphors are common in news reporting on many topics, etc.

Some metaphors are universal while many others reflect cultural variations (Kövecses 2005), and there may also exist even more specifically situated metaphors. According to Lakoff and Johnson (2003) everyday language is permeated with metaphors. They even claim that all thinking and communicating basically is metaphoric.

There is great variety of metaphors and many attempts to classifications have been made. According to Ritchie (2006) some metaphors are more everyday-like (busy as a bee), other poetical (life is a dream), some complex with various meanings (life is a struggle), still others more one-dimensional (the party got out of hand). Root metaphors are those long-lived metaphors permeating cultures, for example conduit, contain and war metaphors (Kövecses 2005). St.Clair (2002) notes that growth-metaphors, playmetaphors, drama-metaphors, machine-metaphor, and time- and room-metaphors for a long time have stamped European thinking.

Anchoring social phenomena in metaphors may serve ideological and legitimating functions. Stibbe (2001) found that metaphors of war and of forest fire dominated Brit- 
ish media reporting on the mad-cow disease and that this justified drastic measures to be taken. Illness and death were two close metaphors in the media reporting on climate change (Höijer 2008). The planet was repeatedly described as "sick" on its way to "die" and a number of animals were about to be "killed" by the climate change. These metaphors not only underline the seriousness of the issue but also relate to our own existential anxiety and, in the specific media context studied, legitimated individual acting to mitigate carbon dioxide.

\section{Objectification}

Objectification makes the unknown known by transforming it into something concrete we may perceive and experience with our senses. It is a kind of materialisation of abstract ideas, which sometimes occur not least in the media, by representing the ideas as concrete phenomena existing in the physical world. "What is perceived replaces what is conceived", writes Moscovici (2000: 51). When, for example, the media attach specific storms, heat waves or floods to climate change the abstract phenomenon is objectified. In science, climate change is an abstract, long-term phenomenon of statistical character, that is, based on probability calculus, which is difficult to grasp experientially. More frequent storms, intensive heat waves, etc., may certainly follow as a result of global warming, but as pointed out by Edwards (2001: 33) "the inherent variability of weather makes it impossible to attribute individual storms, floods, droughts or hurricanes to changes in the global climate".

Objectifying is, according to Moscovici (2000) a much more active process than anchoring which occurs almost automatically each time we are confronted with new phenomena. Objectifying, that is turning an unfamiliar idea into concrete reality requires more effort. Moscovici's (2007/1961) own research on the spread of psychoanalytic thinking in French society is essentially a study of how the abstract and relational concepts of psychoanalysis - the unconscious, ego, libido, complexes, neuroses, etc. - is objectified into concrete elements in public thinking. Going back to our climate change example objectification occurs when ordinary signs in the nature as a summer heat, an autumn storm, or a short winter are regarded as concrete anecdotal evidence of climate change. A new complex and abstract phenomenon is thereby materialised into familiar frames of references and transformed into everyday common sense. That people conflate weather and climate change has been shown in different studies (see Bostrom \& Lashof 2007). Weather, "the state of the atmosphere at a definite time and place with respect to heat or cold, wetness or dryness, calm or storm, clearness or cloudiness" (Bostrom, et al. 1994) replaces climate, "the average course or condition of the weather at a particular place over a period of many years, as exhibited in absolute extremes, means, and frequencies of given departures from these means, of temperature, wind, velocity, precipitation, and other weather elements" (Bostrom, et al. 1994).

Objectification also appears in the media when scientific concepts are transformed into pictures which rather than the original thoughts and ideas become elements of the phenomena. Some years ago, when cloning was on the agenda in the public sphere, media published pictures of "Dolly the sheep" that became an objectification of modern biotechnology or genetic engineering (Bauer \& Gaskell 1999). She was the first mammal to be cloned. Today newspapers expose photographs of retreating glaciers, melting polar 
ice, polar bears and flooding illustrating the consequences of climate change (Smith \& Joffe 2009). That these images objectifies climate change is further shown by the fact that melting glaciers and polar ice, that is, concrete visual objects, are the single largest categories of free associations by the public when confronted with the word global warming (Leiserowitz 2007).

\section{Emotional Objectification}

We may talk about emotional objectification when there is a strong emotional component involved, for example when concrete and frightening images such as people escaping severe floods, dead cattle on parched soil, or dramatic forest fires are repeatedly used by the media in the reporting of climate change (see Höijer 2010; Smith \& Joffe 2009). One should remember that events like this always appear also without climate change, and that it is not these events per se that constitute global warming (see above).

"To objectify is to discover the iconic quality of an imprecise idea or being, to reproduce a concept in an image", writes Moscovici further (1984b: 38), and some visuals in the media may through a process of emotional objectification become icons of more abstract issues. Studies show, for example, that pictures of animals appealing to emotions of compassion, such as sweet and cuddly polar bears on melting ice or young arctic foxes are common in the media reporting of climate change (Höijer 2010; Smith \& Joffe 2009). According to O'Neill and Hulme (in press) polar bears are now the most well understood icon of climate change by the public that is drawn to this image by empathy. In the media these wild predatory animals are conceptualized as innocent victims of climate change by beautiful images of mother and cub, lonely polar bears on a small ice floes or struggling to swim to safety. Their furs are pure and white as to underline their innocence. Alternative pictures of polar bears attacking seals and tearing them into eatable pieces would never objectify climate change in the same way.

\section{Personification}

In objectification through personification an idea or phenomenon is linked to specific persons such as when Freud personifies psychoanalysis or Gandhi political struggle through non-violence. To attach something to well-known public persons is a common discursive mechanism in the media in order to draw attention and popularise courses of events. In the case of climate change we can see how the media draw on familiar domestic meteorologists, key political figures, and celebrities. Smith and Joffe (2009), for example, found that photographs of the former Vice-President Al Gore regularly were accompanying news articles on climate change in the press. He was presented as an ambassador of the climate change and personified not only this issue but also international efforts to solve the problem. Similarly celebrities and popular meteorologists are frequently used as spokesmen for the issue and often represented in ways that personify climate-friendly behaviour (Berglez, Höijer \& Olausson 2009; Smith \& Joffe 2009). As persons they gradually come to materialize or objectify the complex phenomenon of climate change with its relations to nature and human and political life in general. In the end we need only to say, for example, Al Gore, to get people to think about climate change. To this contribute of course also his film "An Inconvenient Truth". 


\section{Discussion}

The focus on representations of [new] societal phenomena and communication makes the theory of social representations highly relevant for media studies. This article has presented, and partly also developed, the basic ideas of the theory, more precisely the communicative mechanisms of anchoring and objectification. It could be noted that a theory here is understood in its deeper sense, that is as "both an approach, a way of looking at social phenomena, and a system describing and explaining them" (Moscovici 1988: 212-213). It could also be noted that in the literature on social representations there are "relatively little guidance on the implications of the theory for the design of empirical research" (Bauer \& Gaskell 1999: 163). Empirically a wide range of methods - both quantitative and qualitative - have been used in social representations research. The point here has not been, however, to discuss specific choices of methods but rather to emphasize the conceptual analytical level and link it to empirical application, in this case by concrete examples from studies of the media and climate change. One of the advantages certainly is that the theory offers the possibility to develop a tight relationship between the theoretical and empirical levels. Another advantage is the comprehensiveness of the theory including a number of communicative mechanisms at different levels of meaning making. For example, the conceptual richness of the concepts of anchoring and objectification in the theory makes it possible to analyze also more hidden levels of the social construction of meaning. In one study Olausson (2010) by focusing on antinomies, emotional anchoring and objectification in a detailed analysis uncovered a concealed but emerging European identity in the media reporting on climate change.

The theory of social representations directs attention to social and cultural thinking of society, how new social cognitions or representations of reality are pushed forward and old ones transformed through communication. The theory benevolent demystifies the question of where the representations come from. They are on one hand related to real changes in the material and symbolic world (technological changes, scientific achievements, courses of events, etc.) and on the other hand to the already existing bodies of social representations in social life, in the media and elsewhere in society.

As with other theories there are, of course also shortcomings with this theoretical approach. Vorlklein and Howarth (2005) have, for example pointed out that questions of power relations are absent in the theory: "We need to analyse how representations may be infused with ideological power to justify status quo and so maintain systems of inequality and exclusion" (ibid: 446). Moscovici does, however, in general terms write about the power of ideas: "it is a proven truth that an idea, no matter what form it assumes, has the power of making us come together, of making us modify our feelings and modes of behaviour and of exercising a constraint over us just as much as any external condition" (Moscovici 1993: 115). Theoretically though the power and ideology aspects certainly need to be developed, for example by combining social representations theory and critical discourse theory.

Another shortcoming, which has been put forth, is that the theory does not address the practices and activities of people or groups of people when they are producing social representations (Potter \& Edwards 1999). Whether or not this is a serious limitation is open for discussion but a theory can of natural reasons not include everything. Furthermore, Voelklein and Howarth (2005) point out that this critique is based on a view that characterizes cognition and action as oppositional but that social representa- 
tions theorists see no such dichotomy. The social and the individual, the cognitive and the cultural, mind and society constitute functional units and social representations are manifested in any social practice.

Notwithstanding these shortcomings the theory of social representations can give valuable contributions to media research. By studying how the media and the public anchor and objectify "new" scientific, political and social issues we obtain knowledge about vital transformations in the thought-systems or collective meaning-making of societies. Ongoing changes are not only structural material processes but also deeply emotional and socio-cognitive.

\section{Referenser}

Altheide, D.L. (2002) Creating Fear. News and the Construction of Crisis. New York: Aldine de Gruyter. Altheide, D. and R.S. Michalowski (1999) 'Fears in the News: A Discourse of Control', The Sociological Quarterly 40(3): 475-503.

Bauer, M. and G. Gaskell (1999) 'Towards a Paradigm for Research on Social Representations', Journal for the Theory of Social Behaviour 29(2): 163-186.

Beck, U. and E. Beck-Gernsheim (2001) Individualization: Institutional Individualism and its Social and Political Consequences. London: Sage.

Berglez, P., Höijer, B. and U. Olausson (2009) 'Individualisation and Nationalisation of the Climate Issue. Two Ideological Horizons in Swedish News, Climate Change and the Media Media', pp. 211-223 in T. Boyce and J. Lewis (eds). New York: Peter Lang.

Billig, M. (1991) Ideology, Rhetoric and Opinions. London: Sage.

Billig, M. (1993) 'Studying the Thinking Society: Social representations, Rhetoric, and Attitudes', pp. 39-62 in G.M. Breakwell and D.V. Canter (eds) Empirical Approaches to Social Representations. New York: Oxford University Press.

Bless, H., Fiedler, K. and F. Struck (2004) Social Cognition. How Individuals Construct Social Reality. Hove: Psychology, cop.

Bostrom, A. and D. Lashof (2007) 'Weather it's Climate Change?', pp. 31-43 in Moser, S.C. and L. Dilling (eds) Creating a Climate for Change. New York: Cambridge University Press.

Bostrom, A., Morgan, M.G., Fischhoff, B., et al. (1994) 'What Do People Know About Global Climate Change? 1. Mental Models', Risk Analysis 14(6): 959-970.

van Dijk, T. (1998) Ideology. A Multidisciplinary Approach. London: Sage.

Deaux, K. and G. Philogéne (eds) (2001) Representations of the Social. Oxford, UK: Blackwell.

Edwards, P.N. (2001) 'Representing the Global Atmosphere: Computer Models, Data and Knowledge about Climate Change', pp. 31-65 in Miller, C. and P. Edwards (eds) Changing the Atmosphere. Cambridge, MA: The MIT Press.

Fairclough, Norman (1992) Discourse and Social Change. Cambridge: Polity Press.

Furedi, F. (2006) Culture of Fear Revisited: Risk-Taking and the Morality of Low Expectation. London: Continuum.

Giddens, A. (1991) Modernity and Self-Identity: Self and Society in the Late Modern Age. Cambridge: Polity Press.

Hall, S. (1986) 'The Problem of Ideology: Marxism without Guarantees', Journal of Communication Inquiry 10(2): 28-44.

Hall, S. (1995) 'The Rediscovery of 'Ideology': Return of the Repressed in the Media Studies', pp. 354-364 in Boyd-Barett, O. and C. Newbold (eds) Approaches to Media. A Reader. London: Arnold.

Hall, S. (1999) 'Encoding/Decoding', pp. 51-61 in Marris, P. and S. Thornham (eds) Media Studies. A Reader. Edinburgh: Edinburgh University Press (originally 1973).

Höijer. B. (2008) 'Sociala representationer i medietexter' [Social Representations in Media Texts], pp. 139164 in M. Ekström (ed.) Mediernas språk. Malmö: Liber.

\section{Acknowledgements}

I would like to thank Peter Berglez and Ulrika Olausson for valuable comments on a draft version. The research has been supported by a grant from Formas, the Swedish Research Council for Environment, Agricultural Sciences, and Spatial Planning. 
Höijer, B. (2010) 'Emotional Anchoring and Objectification in the Media Reporting on Climate Change', Public Understanding of Science 19(6): 717-731.

Jodelet, D. (1991) Madness and Social Representations. London: Harvester Wheatsheaf.

Joffe, H. (2002) 'Social Representations and Health Psychology', Social Science Information 41(4): 559-580.

Kövecses, Z. (2005) Metaphor in Culture: Universality and Variation. Cambridge: Cambridge University Press.

Lakoff, G. and M. Johnson (2003) Metaphors We Live By. Chicago: Chicago University Press.

Leiserowitz, A. (2007) 'Communicating the Risk of Global Warming: American Risk Perceptions, Affective Images, and Interpretive Communities’, pp. 44-63 in Moser, S.C. and L. Dilling (eds) Creating a Climate for Change. New York: Cambridge University Press.

Levidow, L. (2000) 'Pollution Metaphors in the UK Biotechnology Controversy', Science as Culture 9(3): 325-351.

Lippman, W. (1998) Public Opinion. New Brunswick: Transaction Publishers (first published in 1922).

Marková, I. (2003) Dialogicality and Social Representations. The Dynamics of Mind. Cambridge, UK: Cambridge University Press.

Moscovici, S. (1973) 'Foreword', pp. Xiii in C. Herzlich: Health and Illness. A Social Psychological Analysis. London: Academic Press.

Moscovici, S. (1984a) 'The Myth of the Lonely Paradigm: A Rejoinder', Social Research 51: 939-967.

Moscovici, S. (1984b) 'The Phenomenon of Social Representations', pp. 3-69 in R.M. Farr and S. Moscovici (eds) Social Representations. Cambridge, UK: Cambridge University Press.

Moscovici, S. (1988) 'Notes Towards a Description of Social Representations', European Journal of Social Psychology 18: 211-250.

Moscovici, S.(1993) The Invention of Society. Psychological Explanations to Social Phenomena. Cambridge, UK: Polity Press.

Moscovici, S. (2000) Social Representations. Explorations in Social Psychology. Cambridge, UK: Polity Press.

Moscovici, S. (2001) 'Why a Theory of Social Representations?', pp. 8- 35 in K. Deaux and G. Philogéne (eds) Representations of the Social. Oxford, UK: Blackwell Publishers.

Moscovici, S. (2007) Psychoanalysis. Its Image and Its Public. Oxford: Blackwell Publishing (first published 1961).

Olausson, U. (2009) 'Global Warming - Global Responsibility? Media Frames of Collective Action and Scientific Certainty’, Public Understanding of Science 18: 421-436.

Olausson, U. (2010) 'Towards a European Identity? The News Media and the Case of Climate Change', European Journal of Communication 25(2010)14: 138-152.

O’Neill, S. and M. Hulme (2009) 'An Iconic Approach for Representing Climate Change', Global Environmental Change 19(4): 402-410.

Pickering, M. (2001) Stereotyping. The Politics of Representation. Houndsmills: Palgrave.

Potter, J. and D. Edwards (2000) 'Social Representations and Discursive Psychology: from Cognition to Action', Culture \& Psychology 5(4): 447-458.

Ritchie, D.L. (2006) Context and Connection in Metaphor. Hampshire and New York: Palgrave Macmillan.

Robertson, A. (2001) 'Mediated Threats', pp. 61-83 in J. Eriksson (ed) Threat Politics. New Perspectives on Security, Risk and Crises Management. Aldershot, UK: Ashgate.

St. Clair, R.N. (2002) The Major Metaphors of European Thought-Growth, Game, Language, Drama, Machine, Time and Space. New York: The Edwin Mellen Press.

Smith, N.W. and H. Joffe (2009) 'Climate Change in the British Press: The Role of the Visual', Journal of Risk Research 12(5): 647-663.

Stibbe, A. (2001) 'From Flu-Like Virus to Deadly Disease: Ideology and the Media', Journal of Media Psychology 6(2): http:/www. calstatela.edu/faculty/sfischo.

Wagner, W. and N. Hayes (2005) Everyday Discourse and Common Sense. The Theory of Social Representation. Hampshire: Palgrave Macmillan.

Voelklein, C. and C. Howarth (2005) 'A Review of Controversies about Social Representations Theory: A British Debate', Culture \& Psychology 11(4): 431-454.

BIRGITTA HÖIJER, Ph.D., Professor, Faculty of Humanities and Social Sciences, Örebro University, birgitta.hoijer@gmail.com 